\title{
Injury Prevalence, Types and Mechanisms in Football: A Media-based Approach
}

\author{
Rabiu Muazu Musa ${ }^{2 *}$, Isyaku Hassan², Mohamad Razali Abdullah', \\ Mohd Nazri Latiff Azmi ${ }^{2}$ and Siti Musliha Mat-Rasid ${ }^{4}$ \\ 'Department of Credited Core-Curriculum, Center for Fundamental and Continuing Education, Universiti \\ Malaysia Terengganu, Kuala Nerus - 21030, Terengganu, Malaysia; rabiu.muazu@umt.edu.my \\ ${ }^{2}$ Faculty of Languages and Communication, Universiti Sultan Zainal Abidin, Gong Badak Campus, \\ 21300, Kuala Nerus, Terengganu, Malaysia; isyaku87@gmail.com, mnazrix@gmail.com \\ ${ }^{3}$ East Coast Environmental Research Institute, Universiti Sultan Zainal Abidin, \\ Kampung Gong Badak, 21300, Terengganu, Malaysia; razali896@gmail.com \\ ${ }^{4}$ Faculty of Sports Science and Coaching, Universiti Pendidikan Sultan Idris, Perak, \\ Malaysia; sitimusliha89@gmail.com
}

\begin{abstract}
The increase in demand for football players to perform at their best during training and competition results in the escalation of a varying number of football-related injuries. Media reports provide readily as well as timely information on injury-related issues that could assist the stakeholders in decision making before and after a competition. Although, many attempts have been made to quantify football-related injuries in many countries via media, however, little is known on its prevalence, types and mechanisms as reported in Nigerian media. The present study employed a content analysis technique through which 94 football-related news articles from Nigerian newspapers were examined and the most frequently reported injuries are identified. It is demonstrated from the chi-square analysis that the occurrences of football-related injuries are distributed amongst players regardless of their positional role in the game $[\chi 2(60)=41.401$; $p>0.05]$. Moreover, the prevalence in the mechanisms of injuries are disseminated across injury types $[\chi 2(30)=32.203$; $\mathrm{p}>0.05]$. A total of 94 different injuries are reported with knee, ankle, and thigh as the most affected locations. The findings further revealed that strikers have a higher rate of injury occurrences with a total of $52 \%$ as compared to midfielders $20 \%$, defenders $14 \%$, and goalkeepers $12 \%$ whilst $2 \%$ are unidentified. Many of the injuries reported are either fresh $48 \%$ or recurrent $50 \%$ with only $2 \%$ recovery. The present findings could be useful to stakeholders in projecting injury-related problems in football which could guide appropriate action.
\end{abstract}

Keywords: Football, Injury Mechanism, Injury Prevalence, Nigerian Media, Sports News

\section{Introduction}

The increase in demand for football players to perform at their best both during training and competition results in the escalation of a varying number of football-related injuries ${ }^{1}$. It is worth to mention that valid and reliable information becomes necessary in order to prevent as well as manage football-related injuries. The provision of valid information could pave way for understanding the mechanism of injuries occurrences, frequencies and affected sites that could prompt the stakeholders to prepare for the right action both during training and competitions. Media reports provide readily as well as timely information on injury-related issues in the

${ }^{*}$ Author for correspondence 
sporting domain. When an injury occurs in the sports environment, such incident is likely to be reported in the media, and because football-related injuries are infrequent and unexpected, they become newsworthy events and topics of interest amongst the audiences. As such, the media content serves as a potential source of data for investigating football-related information ${ }^{2}$. In fact, it is difficult to conceive of the media operating without a considerable infusion of professional sports content, especially in the twenty-first century ${ }^{3}$.

Several media-based injury analyses with different study designs and data quality have been published over the past years ${ }^{4-7}$. These studies have investigated various dimensions and characteristics of footballrelated injuries, including the types, location, and severity of injuries sustained by football players. Some studies used a combination of retrospective analysis and media-generated datasets while others focused mainly on media-based analysis. For example Fortington et al. ${ }^{5}$, identified a total of 34 football-related fatalities through news media coverage of football-related fatalities in Australia. Through media-based analysis Anderson et al. ${ }^{8}$, also explored the US print media discourse on concussion in American football players. The study concluded that major sports media are beginning to support the notion of health over a masculine warrior narrative. The players' desire to play, based on their actions is obviously becoming less significant than their long-term health and fitness.

Based on information obtained from the public media ${ }^{4}$ described the types, localization and severity of injuries among football players in Germany. According to the study, strains and sprains were the major injury types, and wing-defenders sustained significantly lower rates of groin injury occurrence compared with forwards. The highest rate of injury during matches occurred among wingmidfielders while central-defenders sustained the highest injury occurrence during training periods. Another study focused on the practice-driven investigation of mediabased data to provide information about professional football injuries in Germany ${ }^{9}$. The study identified 57 primary ACL ruptures in the first German football league during the seasons 2007-2008 and 2016-2017. In addition, six recurrent injuries were found.

To minimize underreporting of football-related injuries, a prospective cohort study obtained additional data from the mass media ${ }^{10}$. The study mainly focused on injury characteristics in German football after the shortened winter break in the 2009-2010 seasons. According to the study, high-intensity and competitive training could have further contributed to an increased fatigue level. Recently ${ }^{7}$ conducted a retrospective analysis combined with media-driven data to investigate injury occurrences and mechanisms of head injuries in German football seasons. The study focused on continuously recorded data from the German football magazine "kicker" via which publicly available clinical information was obtained. The study found that most head injuries in professional male football are caused by head-head and elbow-head contacts.

Through media-based registers Schiffner et al. ${ }^{6}$ identified the epidemiology and injury-related lay-off after Anterior Cruciate Ligament Ruptures (ACLRs) in professional male soccer players in Germany using two media-based registers. The number of ACLRs recorded per season varied during the period observed. Goalkeepers are significantly less prone to suffer an ACLR compared to outfield players. According to the study, understanding ACLR mechanisms and knowledge of injury risk factors are necessary, especially among the coaches, medical staff, football players, and insurance and team managers. Interestingly, the results obtained from media-based content are consistent with the reports based on information from the teams medical staff. Therefore, analysis of football-related injuries based on media sources may serve as an alternative for injury reports from clinical perspectives.

The aforementioned studies suggest that mediabased injury reports could provide the athletes, medical practitioners, and sports administrators with useful and interesting information for effective injury management and prevention strategies. In addition, the preceding review suggests that most media-based studies on football-related injuries were conducted in Germany $^{4,6,7,9,10}$, Australia ${ }^{5}$ and the US ${ }^{8}$. Despite the importance of football as an effective means of developing physical activity and fitness, routine data of footballrelated injuries are either inadequate or underreported, particularly in Nigeria ${ }^{11}$. An empirical study on footballrelated injuries is needed particularly in Nigeria since there is often strong interest in these incidents among the spectators, trainers, medical practitioners, as well as sports administrators. Consequently, the current study 
aims to ascertain the prevalence, characteristics as well as mechanisms of football-related injuries reported by some selected reputable Nigerian based newspapers. This could be helpful in the prevention and management of footballrelated injuries. It is also envisaged that this study could provide a valuable conclusion for related decision-making and identify further research directions on the media coverage of football-related injuries.

\section{Methodological Approach to the Problem}

This study uses content analysis to investigate the prevalence, characteristics as well as mechanisms of football-related injuries reported by the major Nigerian newspapers. Content analysis is chosen as it centers on media message characteristics. It also provides specific media content that can be analyzed to produce valid results and provide useful information. It looks at communication via text and allows for both quantitative and qualitative analyses; and it is considered a relative research method based on facts, as opposed to Discourse Analysis ${ }^{12}$. According to Cohen et al. ${ }^{13}$, "content analysis takes texts and analyses, reduces and interrogates them into summary form through the use of both pre-existing categories and emergent themes in order to generate or test a theory" (p. 476).

\section{Sampling Technique and Period of Coverage}

Purposive sampling technique was used to select the news articles. It refers to a form of non-probability sampling in which decisions concerning the elements to be included in the sample are taken by the researcher. Purposive sampling enables researchers to select a sample based on the purpose of the study ${ }^{14,15}$. Five national newspapers with the highest readership and online popularity were selected for analysis: Vanguard, Punch, The Nation, Sun, and This Day. These newspapers are the top daily English language publications (Top Ten Nigerian Newspapers, 2019). Only football-related news articles published in the selected newspapers between January 2015 and September 2019 were selected. This represents the period within which various football tournaments were carried out, including Africa Cup of Nations and World Cup Championships. This time frame was chosen to make the data into a manageable size for analysis.

\section{Parameters Search}

The researchers conducted an internet-based search for football-related news articles on the websites of the respective newspapers using Football, soccer and Injury as keywords. All newspaper articles identified using this method were included in the content analysis. Any article that focuses upon report about football-related injury fulfils the inclusion criteria. Each article in the original sample was read for relevance. The contexts of coverage were studied based on headlines and news content. This study considers newspaper articles because newspaper readers have control over their news consumption as they can attend to the news at any time ${ }^{16}$. Newspapers represent a readily available source of data which are more detailed and accurate than other traditional datasets ${ }^{2}$. Though data generated from news content is considered qualitative, they can be quantified to obtain valid results. It is clearly evinced in the work of Hsieh et al. ${ }^{17}$, that content analysis is classified as primarily a quantitative versus qualitative research method. Moreover, searches were made in various databases that included PubMed, Science Direct, SPORT Discus as well as Scopus in order to substantiate the findings of the present investigation.

\section{Coding Procedure}

Before interpretations, all decisions regarding measurement and coding must be made ${ }^{14}$. In this study, the coding characteristics included: types of football-related injury, the extent of coverage, news sources, and the teams' responses. At the preliminary stage of data coding, all the selected articles were summarized, and a database was generated. Every single detail of the news articles was studied and coded using a hierarchical code system. The advantage of hierarchical coding is the amount of information it can represent in a relatively small number of digits ${ }^{17}$. A second coder was hired to ensure reliability in this study. To assess the level of agreement between ratings on the article coding, Cohen's kappa test was used to measure inter-coder agreement for categorical items. 


\section{Reliability Testing}

The accuracy of news content has been recognized in providing valuable information about the dimensions and occurrences of accidental injuries ${ }^{2}$. In this study, particular attention was paid to the themes relating to football-related injuries, the extent of coverage, news sources, and the teams' responses within the selected articles throughout the coding process. In addition, the themes were critically analyzed to avoid re-production of the media content or revealing the dominant themes containing certain football-related information. Specifically, the researchers aimed to explore the documented news construction related to football-related injuries which contain the emerging themes through the coding process ${ }^{18}$. This procedure consists of subjective judgement but using inter-coder reliability resulted in an empirical and systematic approach ${ }^{19}$.

\section{Data Analysis}

In the present study, the chi-square test for independence which essentially measures whether distributions of categorical variables differ from each another is employed to examine the prevalence, mechanisms as well as the localization of injuries as reported by the selected news papers. It is worth noting that a very small chi-square test statistic suggests that the observed data has the ability to fit the expected data exceptionally well. In other words, there is an association between the dataset. Conversely, a very large chi-square test statistic implies that the data does not fit very well. In other words, no association existed between the dataset. In this study, the test is applied to ascertain the occurrence of football-related injuries with respect to the mechanism (fresh, recovery or recurrent), types, playing positions of the players as well as anatomical localization of the injuries. All inferences were set at an alpha (a) level of $\leq 0.05$ using the SPSS statistical software package (SPSS Inc., Chicago, IL, USA, 20.0).

\section{Results}

Table 1 tabulates the distributions of players' positions in relation to the various types of injuries sustained. Although, no statistically significant differences were observed between the players' position and the types of injuries sustained ( $\mathrm{p}=0.968)$, nonetheless, it could be seen from the table that knee, ankle, as well as thigh, are

Table 1. Players' positions and injuries distribution

\begin{tabular}{|c|c|c|c|c|c|c|}
\hline \multirow{2}{*}{ Types of injury } & \multicolumn{6}{|c|}{ Players Position } \\
\hline & UNID. F (\%) & FW. F (\%) & MD. F (\%) & DF. F (\%) & GK. F (\%) & Total \\
\hline Knee & $0(0)$ & $10(40)$ & $6(24)$ & $4(16)$ & $5(20)$ & 25 \\
\hline Foot & $0(0)$ & $2(50)$ & $0(0)$ & $0(0)$ & $2(50)$ & 4 \\
\hline Shoulder & $0(0)$ & $3(75)$ & $0(0.00 \%)$ & $0(0)$ & $1(25)$ & 4 \\
\hline Ankle & $0(0)$ & $8(57.10)$ & $2(14.30)$ & $3(21.4 \%)$ & $1(7.10)$ & 14 \\
\hline Thigh & $2(8)$ & $12(48)$ & $5(20)$ & $5(20)$ & $1(4)$ & 25 \\
\hline Genital & $0(0)$ & $1(100)$ & $0(0)$ & $0(0)$ & $0(0)$ & 1 \\
\hline Muscle & $0(0)$ & $1(100)$ & $0(0)$ & $0(0)$ & $0(0)$ & 1 \\
\hline Hamstring & $0(0)$ & $5(71.40)$ & $2(28.60)$ & $0(0)$ & $0(0)$ & 7 \\
\hline Groin & $0(0)$ & $0(0)$ & $2(66.70)$ & $1(33.30)$ & $0(0)$ & 3 \\
\hline Wrist & $0(0)$ & $1(50)$ & $1(50)$ & $0(0)$ & $0(0)$ & 2 \\
\hline Back & $0(0)$ & $1(100)$ & $0(0)$ & $0(0)$ & $0(0)$ & 1 \\
\hline Rib & $0(0)$ & $1(100)$ & $0(0)$ & $0(0)$ & $0(0)$ & 1 \\
\hline Hip & $0(0)$ & $1(100)$ & $0(0)$ & $0(0)$ & $0(0)$ & 1 \\
\hline Leg & $0(0)$ & $2(66.70)$ & $0(0)$ & $0(0)$ & $1(33.30)$ & 3 \\
\hline Calf & $0(0)$ & $1(100)$ & $0(0)$ & $0(0)$ & $0(0)$ & 1 \\
\hline Arm & $0(0)$ & $0(0)$ & $1(100)$ & $0(0)$ & $0(0)$ & 1 \\
\hline Overall Total & $2.10 \%$ & $52.10 \%$ & $20.20 \%$ & $13.00 \%$ & $11.70 \%$ & 94 \\
\hline
\end{tabular}

$\left[\chi^{2}(60)=41.401 ; \mathrm{p}>0.05\right]$ (Distribution of injuries between positions) 
the most affected locations across all the playing positions with a total prevalence rates of 25,14 and 25 respectively.

Figure 1 displays the scatter plots of injuries distribution with respect to the positional roles of the players. It could be observed from the figure that strikers recorded the highest injuries with numerous types of injuries followed by midfielder's goalkeepers and defenders respectively.

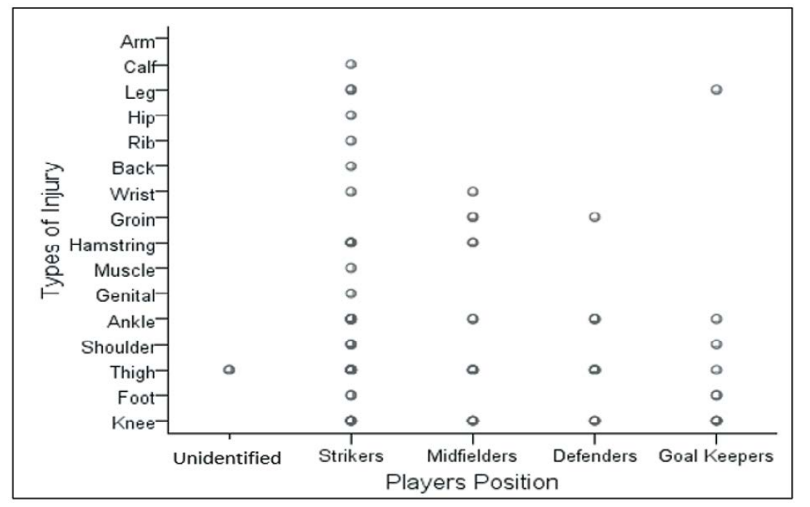

Figure 1. Distribution of injuries based on players' positions.

Table 2 presents the distributions of the injuries and their various mechanisms. It could be observed that no significant difference between the various injuries sustained and their mechanisms exist $(\mathrm{p}=0.358)$ however, $50 \%$ of the injuries sustained are recurrent whilst $48 \%$ are fresh with only $2 \%$ reported as recovery.

Table 2. Distributions of injury types and their mechanisms

\begin{tabular}{|c|c|c|c|}
\hline & \multicolumn{3}{|c|}{ Injury Status } \\
\hline Types of injury & Fresh F (\%) & $\begin{array}{c}\text { Recovery } \\
\text { F (\%) }\end{array}$ & $\begin{array}{c}\text { Recurrent } \\
\text { F (\%) }\end{array}$ \\
\hline Knee & $14(56)$ & $0(0)$ & $11(44)$ \\
\hline Foot & $4(100)$ & $0(0)$ & $0(0)$ \\
\hline Shoulder & $1(25)$ & $1(25)$ & $2(50)$ \\
\hline Ankle & $7(50)$ & $0(0)$ & $7(50)$ \\
\hline Thigh & $11(44)$ & $1(4)$ & $13(52)$ \\
\hline Genital & $1(100)$ & $0(0)$ & $0(0)$ \\
\hline Muscle & $1(100)$ & $0(0)$ & $0(0)$ \\
\hline Hamstring & $4(57.10)$ & $0(0)$ & $3(42.90)$ \\
\hline Wrist & $0(0)$ & $0(0)$ & $3(100)$ \\
\hline Back & $0(0)$ & $0(0)$ & $1(100)$ \\
\hline Rib & $1(100)$ & $0(0)$ & $0(0)$ \\
\hline Hip & $0(0)$ & $0(0)$ & $1(100)$ \\
\hline
\end{tabular}

\begin{tabular}{|c|c|c|c|}
\hline Leg & $0(0)$ & $0(0)$ & $3(100)$ \\
\hline Calf & $0(0)$ & $0(0)$ & $1(100)$ \\
\hline Arm & $1(100)$ & $0(0)$ & $0(0)$ \\
\hline Overall Total (\%) & $\mathbf{4 7 . 9 0 \%}$ & $\mathbf{2 . 1 0 \%}$ & $\mathbf{5 0 . 0 0 \%}$ \\
\hline
\end{tabular}

$[\chi 2(30)=32.203 ; p>0.05]$ (Distribution of injuries based on mechanism)

Figure 2 highlights the mechanisms of injury occurrences and their types. It could be seen from the figure that the mechanisms of the injuries differ to some extent across the injury types. Highest prevalence of injuries namely, hamstring, ankle, thigh, foot as well as knee are reported to be freshly sustained. Conversely, more frequent injuries viz.leg, groin, wrist, shoulder, hamstring, ankle, thigh, and knee are recurrent in nature. A fewer injuries specifically thigh and shoulder are reported as recovery.

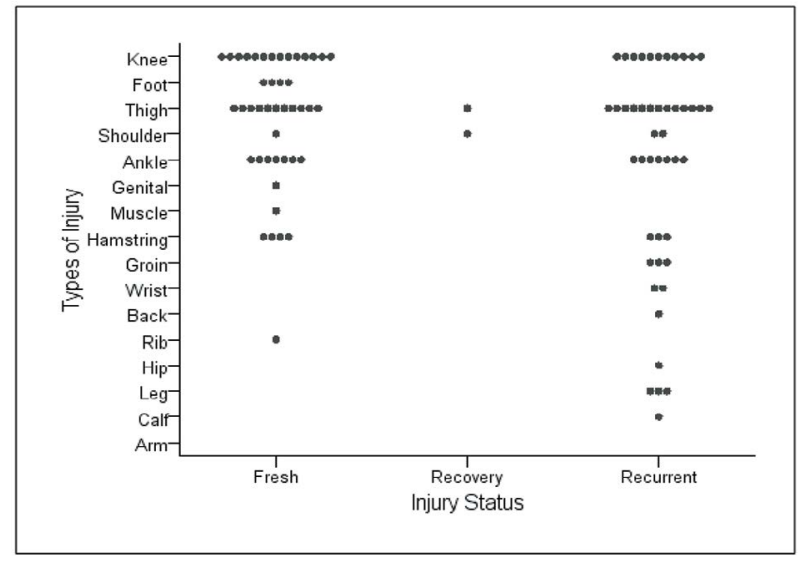

Figure 2. Mechanisms of injuries types and their distribution.

\section{Discussion}

The present study aimed at examining the prevalence, characteristics as well as mechanisms of football-related injuries reported by some selected reputable Nigerian based newspapers. It was established from the findings of the study that the occurrences of football-related injuries are distributed amongst players irrespective of the role they play in the game (Table 1). Moreover, the prevalence in the mechanisms of injuries i.e. fresh, recurrent or recovery is disseminated across various injury types with recurrent and fresh reported as highest whilst fewer injuries are reported as recovery (Table 2). It was also observed from the study that knee, ankle, and thigh injuries are the most affected locations. The findings 
further revealed that the prevalence of injury occurrences is highly attributed to strikers followed by midfielders, defenders and goalkeepers respectively (Figure 1). It is worth noting that some specific injuries namely, hamstring, ankle, thigh, foot as well as knee are reported to be freshly suffered by the players. However, leg, groin, wrist, shoulder, hamstring, ankle, and thigh as well as knee injuries are found to be recurrent in nature whilst thigh and shoulder are reported as recovery (Figure 2).

The findings reported in this study indicated that knee injury is the most commonly reported football-related injury in Nigerian newspapers, followed by an ankle injury and hamstring injury. Based on the assumption of Agenda-setting theory, this information could provide the public, particularly medical personnel, team managers and the athletes, with a signal about the most affected injury locations in football through the transfer of salience ${ }^{20}$ with regard to a knee injury, ankle injury and hamstring injury. Because injuries have a considerable influence on the performance of professional soccer players ${ }^{6}$, related information could help design proper management and prevention strategies. Identifying location differences in football injury occurrences could be much important to medical practitioners when considering the preventive measures and management ${ }^{4}$.

Interestingly, the findings of this study are consistent with those obtained in most prospective studies ${ }^{21-23}$. These studies specifically focused on the types and locations of a football injury. Some of the studies concluded that the majority of football-related injuries affect the lower extremities ${ }^{21,22}$. Junge, et al. ${ }^{24}$ found that the most frequently injured body parts include the thigh, lower leg, head, knee, and ankle. This consistency, particularly with regard the knowledge of injury risk factors, signifies the importance of media sources in the analysis of footballrelated injuries as an alternative for injury reports from prospective and clinical perspectives ${ }^{6}$. Increased awareness of the importance of fair play may contribute to the prevention of football-related injuries ${ }^{24}$.

In the context of injury occurrences with respect to the positional requirement, the present findings is congruent to the findings of the previous literature in which a greater prevalence of injuries in football were observed to be sustained by strikers in comparisons to other positions ${ }^{25,26}$. Moreover, the study findings are in accordance with previous findings which reported that forwards were ranked higher in a state-local league as compared to any other position ${ }^{27}$. The strikers or otherwise forwards have been previously reported to be lighter and as such are expected to cover a long distance during the game and convert many attempts to a goal ${ }^{28}$. This positional requirement predisposed the players to a varying degree of injuries ranging from a minor knock to a severe problem that could sideline them for a long period of time. Likewise, a study carried out by Jordan et al..$^{29}$, documented that midfielders have equally recorded a significant proportion of prevalence of injuries in a soccer team. Defenders have also been previously reported to be prone to injury occurrences due to their role in guiding as well as marking their opponents which often resulted in having constant contact with the opposition players that may bring about injury-related problems ${ }^{30}$.

The mechanisms of the injury occurrences in the present study have demonstrated that a larger proportion of the injury sustained is either fresh or recurrent. The game of football involves many tactical and technical skills such as tackling, running, being tackled, and shooting, twisting and turning, jumping as well as landing. The execution of the aforesaid skills could be challenging and if a player is unable to execute the skill appropriately or being tackled improperly, the injury often emanates ${ }^{31}$. Although, the study results indicated that a diverse range of injuries are reported as fresh or recurrent, however, a greater percentage of such injuries are lower extremities related injuries. The lower extremities injuries are often encountered during tackling due to the difficulty of the players to respond quickly enough to avoid such swift and unpredictable movement involves in the game of football. It has been documented by the preceding researchers that a higher than two-thirds of all injuries in football occur to the lower extremities, specifically the ankle, knee, thigh, hip, groin as well as foot which renders the players predispose to acute as well as chronic suffering of such injuries ${ }^{32}$.

\section{Conclusion and Recommendations}

The current study investigated the prevalence, characteristics as well as mechanisms of football-related injuries reported by some selected reputable Nigerian based newspapers. It is evident in this study that the media could provide valuable information about football injuries, particularly with respect to the anatomical location of the injury, frequency as well as the mechanism which could be useful to medical 
practitioners, football teams, and the athletes themselves. It is demonstrated from the findings of the present study that football-related injuries may occur to players irrespective of the role they play in the game. Moreover, the prevalence in the mechanisms of injuries i.e. fresh, recurrent or recovery is disseminated across various injury types with recurrent and fresh reported as highest whilst fewer injuries are reported as recovery. It was also observed from the study that knee, ankle, and thigh injuries are the most affected locations. The findings further revealed that the prevalence of injury occurrences is highly attributed to strikers followed by midfielders, defenders and goalkeepers respectively. The findings discussed in the present study could serve useful to all the stakeholders in sporting domain in understanding the pattern, mechanisms as well as the anatomical positions that are prone to injuries specifically in the sport of football which will go a long way in guiding action and making necessary changes both during training and competitions in order to avert the menace of the injury occurrences.

It is worth to accentuate that media-based analysis of football-related injuries could supplement other methods, such as prospective and retrospective analyses. The timeliness, accessibility, and permanency of the media content make it especially useful in analyzing football-related injuries. According to this study, footballrelated injuries are accorded much salience in Nigerian newspapers. The infrequency of football-related injuries restrains the collection of relatively larger samples within the data collection period, and hence future research may consider a longer period of data collection. In addition, only online newspapers were considered while other forms of media such as blogs and social media were viewed as too subjective for this study. Nevertheless, these forms of media could be useful alternative sources of data in future research. Despite the lack of factual football-related injury data in Nigeria, research of this nature is either lacking or inadequate in the country. This study provides a better understanding of football-related injuries through media content, which could further be used for prospective investigation of injury occurrences in football, particularly in the Nigerian context.

\section{Conflicting Interests}

The authors declared none.

\section{Ethical Approval}

Not required

\section{References}

1. Asperti AM, Fernandes TL, Pedrinelli A, Hernandez AJ. Sports injuries among amateur athletes at a Brazilian University. Acta Ortop. Bras. 2017; 25:93-98. https://doi.org/10.1590/1413-785220172502165651. PMid: 28642659, PMCid: PMC5474421.

2. Berchialla P, Scarinzi C, Snidero S, Rahim Y, Gregori D. Information extraction approaches to unconventional data sources for "Injury Surveillance System": The case of newspapers clippings. J. Med. Syst. 2012; 36:475-81. https://doi. org/10.1007/s10916-010-9492-1. PMid: 20703703.

3. Rowe D, Smelser NJ, Baltes PB. Mass media and sports. Int. Encycl. Soc. Behav. Sci. 2001. https://doi.org/10.1016/ B0-08-043076-7/04348-5.

4. Leventer L, Eek F, Hofstetter S, Lames M. Injury patterns among elite football players: A media-based analysis over 6 seasons with emphasis on playing position. Int. J. Sports Med. 2016; 37:898-908. https://doi. org/10.1055/s-0042-108201. PMid: 27467906.

5. Fortington LV, Bekker S, Finch CF. Online news media reporting of football-related fatalities in Australia: A matter of life and death. J. Sci. Med. Sport. 2018; 21:245-49. https://doi.org/10.1016/j.jsams.2017.06.015. PMid: 28663137.

6. Schiffner E, et al. Anterior cruciate ligament ruptures in German elite soccer players: Epidemiology, mechanisms, and return to play. Knee. 2018; 25:219-25. https://doi. org/10.1016/j.knee.2018.01.010. PMid: 29478904.

7. Beaudouin F, Aus der Fünten K, Tröß T, Reinsberger C, Meyer T. Head injuries in professional male football (soccer) over 13 years: 29\% lower incidence rates after a rule change (red card). Br. J. Sports Med. 2019; 53:94852. https://doi.org/10.1136/bjsports-2016-097217. PMid: 28646098.

8. Anderson E, Kian EM. Examining media contestation of masculinity and head trauma in the National Football League. Men Masc. 2012; 15:152-73. https://doi. org/10.1177/1097184X11430127.

9. Krutsch W, et al. High return to competition rate following ACL injury-A 10-year media-based epidemiological injury study in men's professional football. Eur. J. Sport Sci. 2019; 1-9. https://doi.org/10.1080/17461391.2019.1648557. PMid: 31354061. 
10. Fünten K aus der, Faude O, Lensch J, Meyer T. Injury characteristics in the German professional male soccer leagues after a shortened winter break. J. Athl. Train. 2014; 49:78693. https://doi.org/10.4085/1062-6050-49.3.51. PMid: 25365132, PMCid: PMC4264651.

11. Owoeye OBA, Aiyegbusi AI, Fapojuwo OA, Badru OA, Babalola AR. Injuries in male and female semi-professional football (soccer) players in Nigeria: Prospective study of a National Tournament. BMC Res. Notes. 2017; 10:133. https://doi.org/10.1186/s13104-017-2451-x. PMid: 28327163, PMCid: PMC5361784.

12. McCombs M. New frontiers in agenda setting: Agendas of attributes and frames. Mass Commun. Rev. 1997; 24:32-52.

13. Cohen L, Manion L, Morrison K. Research Methods in Education, 6th ed., London and New York, NY: Routledge Taylor and Francis Group; 2007. https:/gtu.ge/Agro-Lib/ RESEARCH\%20METHOD\%20COHEN\%20ok.pdf.

14. Neuendorf KA. The content analysis guidebook. Sage. 2016. https://doi.org/10.4135/9781071802878. PMid: 28717000, PMCid: PMC5519128.

15. Palys T. Purposive sampling. Sage Encycl. Qual. Res. Methods. 2008; 2:697-98. https://www.sfu.ca/ palys/ Purposive\%20sampling.pdf.

16. Soroka SN. Agenda-Setting Dynamics in Canada. UBC Press, Vancouver-Toronto; 2002. https://www.ubcpress.ca/ asset/12470/1/9780774809580.pdf.

17. Hsieh H-F, Shannon SE Three approaches to qualitative content analysis. Qual. Health Res. 2005; 15:1277-88. https:// doi.org/10.1177/1049732305276687. PMid: 16204405.

18. Sparkes A. Writing and the textual construction of realities: Some challenges for alternative paradigms research in physical education. Res. Phys. Educ. Sport Explor. Altern. Visions. 1992; 271-97.

19. Jordan W, Miller SR. Inter-rater agreement in analysis of open-ended responses: Lessons from a mixed methods study of principals. Knowl. Creat. Diffus. Util. 2003; 15.

20. McCombs ME, Shaw DL. The agenda-setting function of mass media. Public Opin. Q. 1972; 36: 176-87. https://doi. org/10.1086/267990.

21. Söderman K, Adolphson J, Lorentzon R, Alfredson $H$. Injuries in adolescent female players in European football: A prospective study over one outdoor soccer season. Scand. J. Med. Sci. Sports. 2001; 11:299-304. https://doi. org/10.1034/j.1600-0838.2001.110508.x. PMid: 11696215.
22. Hägglund M. Epidemiology and prevention of football injuries. Linkoping Universtiy: Faculty of Health Sciences, Linkoping: Sweden; 2007. https://www.diva-portal.org/ smash/get/diva2:23280/FULLTEXT01.pdf.

23. Constantinou D. Football injuries-surveillance, incidence and prevention. Contin. Med. Educ. 2010; 28:220-25.

24. Junge A, Dvorak J, Graf-Baumann T. Football injuries during the World Cup 2002. Am. J. Sports Med. 2004; 32:23-27. https://doi.org/10.1177/0363546503261246. PMid: 14754856.

25. Carling C, Orhant E, LeGall F. Match injuries in professional soccer: Inter-seasonal variation and effects of competition type, match congestion and positional role. Int. J. Sports Med. 2010; 31:271-76. https://doi. org/10.1055/s-0029-1243646. PMid: 20166007.

26. Fachina R, Andrade M, et al. Descriptive epidemiology of injuries in a Brazilian premier league soccer team. Open Access J. Sport. Med. 2013; 4:171. https://doi.org/10.2147/ OAJSM.S44384. PMid: 24379722, PMCid: PMC3871049.

27. Azubuike SO, Okojie OH. An epidemiological study of football (soccer) injuries in Benin City, Nigeria. Br. J. Sports Med. 2009; 43:382-86. https://doi.org/10.1136/ bjsm.2008.051565. PMid: 18927169.

28. Abdullah MR, Musa RM, Kosni NA, Maliki A, Haque M. Profiling and distinction of specific skills related performance and fitness level between senior and junior Malaysian youth soccer players. Int. J. Pharm. Res. 2016; 8:64-71.

29. Morgan BE, Oberlander MA. An examination of injuries in major league soccer: The inaugural season. Am. J. Sports Med. 2001; 29:426-30. https://doi.org/10.1177/0363546501 0290040701 . PMid: 11476380.

30. Abdullah MR, Musa RM, Maliki A, Suppiah PK, Kosni NA. Relationship of physical characteristics, mastery and readiness to perform with position of elite soccer players. Int. J. Adv. Eng. Appl. Sci. 2016; 1:8-11.

31. Wong P, Hong Y. Soccer injury in the lower extremities. Br. J. Sports Med. 2005; 39:473-82. https://doi.org/10.1136/ bjsm.2004.015511. PMid: 16046325, PMCid: PMC1725275.

32. Kay MC, et al. The epidemiology of severe injuries sustained by National Collegiate Athletic Association Student-Athletes, 2009-2010 through 2014-2015. J. Athl. Train. 2017; 52:117-28. https://doi.org/10.4085/1062-605052.1.01. PMid: 28118030, PMCid: PMC5343524. 